\title{
Crosstalk between mitochondrial ROS and depolarization in the potentiation of TRAIL-induced apoptosis in human tumor cells
}

\author{
MIKI SUZUKI-KARASAKI ${ }^{1}$, TOYOKO OCHIAI ${ }^{1}$ and YOSHIHIRO SUZUKI-KARASAKI ${ }^{2,3}$ \\ ${ }^{1}$ Department of Dermatology, Nihon University Surugadai Hospital, ${ }^{2}$ Division of Physiology, \\ Department of Biomedical Sciences, Nihon University School of Medicine, ${ }^{3}$ Innovative Therapy \\ Research Group, Nihon University Research Institute of Medical Science, Tokyo 173-8610, Japan
}

Received September 30, 2013; Accepted November 13, 2013

DOI: $10.3892 /$ ijo.2013.2215

\begin{abstract}
We previously showed that membrane-depolarizing agents such as $\mathrm{K}^{+}$and ATP-sensitive potassium $\left(\mathrm{K}_{\mathrm{ATP}}\right)$ channel inhibitors potentiate tumor necrosis factor-related apoptosis-inducing ligand (TRAIL)-induced apoptosis in human melanoma cells, but not in normal melanocytes. In this study, we investigated whether the tumor-selective effect of depolarization was observed among different tumor cell types and the mechanisms by which depolarization potentiates death pathways. We found that $\mathrm{K}^{+}$and $\mathrm{K}_{\mathrm{ATP}}$ channel inhibitors elicited similar apoptosis-potentiating effects in human tumor cells with different origins, including leukemia, melanoma and lung cancer cells. In contrast, minimal potentiation of apoptosis was observed in non-transformed lung cells. The potentiation was associated with increased mitochondrial and endoplasmic reticulum stress death pathways. Upregulation of surface TRAIL receptor-2 expression and modulation of the caspase-3 activation pathway seemed to play roles in the enhancement of death signaling. Moreover, the results showed that depolarization and mitochondria-derived reactive oxygen species (mROS) mutually regulated one another. Depolarization potentiated TRAIL-induced mROS accumulation. Conversely, scavenging of mROS by the antioxidant MnTBaP reduced depolarization, whereas mROS accumulation caused by metabolic inhibitors potentiated the depolarization. These findings suggest a positive loop between depolarization and mROS accumulation. This may provide a rationale for the tumor-selective cytotoxicity and/or potentiation of TRAIL cytotoxicity of a wide variety of ROS-producing substances in different types of tumor cells.
\end{abstract}

Correspondence to: Dr Yoshihiro Suzuki-Karasaki, Division of Physiology, Department of Biomedical Sciences, Nihon University School of Medicine, 30-1 Oyaguchikami-cho, Itabashi-ku, Tokyo 173-8610, Japan

E-mail: suzuki.yoshihiro@nihon-u.ac.jp

Key words: tumor necrosis factor-related apoptosis-inducing ligand, depolarization, $\mathrm{K}^{+}$, ATP-sensitive potassium, reactive oxygen species, mitochondria, apoptosis

\section{Introduction}

Tumor necrosis factor-related apoptosis-inducing ligand (TRAIL), a member of the tumor necrosis factor cytokine family, selectively induces cancer cell death by binding to two death domain-containing receptors, TRAIL-receptor 1 (TRAIL-R1)/death receptor (DR) 4 and TRAIL-R2/DR5 $(1,2)$. Binding of TRAIL to TRAIL-R1 or TRAIL-R2 expressed on the cell surface initiates the extrinsic apoptotic pathway, in which caspase- 8 plays a key role $(3,4)$. Active caspase- 8 directly activates the effector caspase- $3,-6$ and -7 that execute the apoptotic process. Caspase- 8 can also engage the intrinsic (mitochondrial) apoptotic pathway by cleaving and activating the pro-apoptotic Bcl-2-family molecule Bid (5). Truncated Bid activates Bax and Bak, leading to their oligomerization and pore formation in the outer mitochondrial membrane through which cytochrome $c$ is released into the cytosol. The released cytochrome $c$ binds to another pro-apoptotic protein Apaf-1, leading to assembly of the apoptosome and the resulting activation of caspase-9 (6). Caspase-9 also activates caspase-3, -6 and -7 , thereby providing a positive feedback loop to the caspase-8-induced apoptotic events. In a few type I cancer cells, the extrinsic pathway is sufficient to commit the cells to apoptosis, while in most type II cancer cells, the activation of caspase- 8 is low and amplification by the intrinsic mitochondrial pathway is necessary to evoke substantial apoptosis (7).

Since TRAIL induces apoptosis in a variety of transformed and cancer cells, but not in normal cells, it is promising for cancer treatment. However, some cancer cell types, such as malignant melanoma, glioma, osteosarcoma and non-small cell lung cancer cells, are resistant to TRAIL-induced apoptosis despite expression of the death-inducing TRAIL-Rs on their cell surface (8). Moreover, TRAIL-responsive tumors acquire a resistant phenotype that renders TRAIL therapy ineffective. Therefore, overcoming the TRAIL-resistance of cancer cells is necessary for effective TRAIL therapy, and drugs that can potentiate TRAIL effectiveness are urgently required.

Depolarization has been shown to be an early event in the apoptosis induced by diverse agents, including Fas (9), rotenone (ROT) (10) and arsenic trioxide (11), and is considered to play an important pro-apoptotic role. On the contrary, depolarization has also been shown to exhibit anti-apoptotic effects. Various membrane-depolarizing agents, including ouabain, tetraeth- 
ylammonium (TEA) and veratridine, protect Purkinje cells against apoptosis (12). These observations suggest that depolarization can act in both pro-apoptotic and anti-apoptotic manners depending on the cell types and apoptotic stimuli involved. However, the cellular and molecular mechanisms underlying these dual functions are unclear. Compared with other DRs, the role of depolarization in TRAIL-induced apoptosis is poorly documented. We previously showed that robust depolarization is an early event during TRAIL-induced apoptosis in human melanoma cells. Moreover, membrane-depolarizing agents including $\mathrm{K}^{+}$and ATP-sensitive potassium $\left(\mathrm{K}_{\mathrm{ATP}}\right)$ channel inhibitors such as glibenclamide (GLB) and U37883A (U37) markedly potentiated TRAIL-induced apoptosis (13). This depolarization-mediated potentiation of apoptosis was associated with upregulation of the mitochondrial death pathway and endolasmic reticulum (ER) stress-mediated death pathway involving caspase-12. Strikingly, melanocytes were insensitive to TRAIL-induced depolarization and apoptosis as well as the potentiation by membrane-depolarizing drugs (13). These observations suggest a tumor-selective role of depolarization in regulating apoptosis. However, it remains to be elucidated whether this effect of depolarization is characteristic of melanoma cells or a general feature of different tumor cell types and how depolarization affects these two death pathways. In the present study, we addressed these questions by performing similar experiments in human Jurkat leukemia cells and A549 lung cancer cells. In addition, we examined the possible role of mitochondria-derived reactive oxygen species (mROS) in the potentiation of apoptosis, since our previous study showed that mROS mediated mitochondrial and ER dysfunctions in Jurkat cells during TRAIL-induced apoptosis (14). The results showed that the previous observations in melanoma cells can essentially be expanded to other tumor cells with different origins. Moreover, we found that depolarization and mROS mutually control one another. Importantly, our results suggest a positive loop between depolarization and mROS through DR5 expression.

\section{Materials and methods}

Reagents. Soluble recombinant human TRAIL and the $\mathrm{K}^{+}$ channel inhibitors GLB, U37, TEA, 5-hydroxydecanoate (HD), $\alpha$-dendrotoxin (DTX) and charybdotoxin (CTX) were obtained from Enzo Life Sciences (San Diego, CA, USA). Throughout this study, TRAIL was generally used at concentrations of $6.3-100 \mathrm{ng} / \mathrm{ml}$ and the $\mathrm{K}^{+}$channel inhibitors were used at $100 \mu \mathrm{M}$. ROT, antimycin A, oligomycin and carbonylcyanide p-trifluoromethoxyphenylhydrazone (FCCP) were obtained from Sigma-Aldrich (St. Louis, MO, USA). Mn(III) tetrakis (4-benzoic acid) porphyrin chloride (MnTBaP), pan-caspase inhibitor z-VAD-fluoromethylketone (FMK), caspase-3/7-specific inhibitor z-DEVD-FMK, caspase-8-specific inhibitor z-IETD-FMK and caspase-9-specific inhibitor z-LEHD-FMK were purchased from Merck Japan (Tokyo, Japan). The caspase-12-specific inhibitor z-ATAD-FMK and caspase-4-specific inhibitor z-LEVD-FMK were purchased from BioVision (Mountain View, CA, USA). The reagents were dissolved in dimethylsulfoxide and diluted with Hank's balanced salt solution (HBSS) to a final dimethylsulfoxide concentration of $<0.1 \%$ before use. Antimycin A was used with $0.5 \mu \mathrm{g} / \mathrm{ml}$ oligomycin to inhibit complex III activity of the electron transport chain (referred as to AM).

Cell culture. Human Jurkat leukemia cells were obtained from RIKEN BioResource Center Cell Bank (Tsukuba, Japan) and cultured in high glucose-containing RPMI-1640 medium (Sigma-Aldrich) supplemented with $10 \%$ fetal bovine serum (FBS; Sigma-Aldrich) in a 5\% $\mathrm{CO}_{2}$-containing atmosphere. Human A549 lung cancer cells and human fetal fibroblast-like lung cell WI-38-40 were obtained from Health Science Research Resource Bank (Osaka, Japan) and grown in low glucosecontaining Dulbecco's modified Eagle's medium supplemented with $10 \%$ FBS in a $5 \% \mathrm{CO}_{2}$-containing atmosphere. The cells were harvested by incubation in $0.25 \%$ trypsin-EDTA medium (Gibco-Invitrogen, Carlsbad, CA, USA) for $5 \mathrm{~min}$ at $37^{\circ} \mathrm{C}$.

Measurement of depolarization. Depolarization was measured by flow cytometry using bis-oxonol (Enzo Life Sciences), an anionic dye that shows increased fluorescence intensity upon membrane depolarization, as previously described (13). Briefly, $4 \times 10^{5}$ cells suspended in $500 \mu 1$ of HBSS were incubated with $100 \mathrm{nM}$ dye for $15 \mathrm{~min}$ at $37^{\circ} \mathrm{C}$, and then incubated with the agents to be tested for $2-4 \mathrm{~h}$ at $37^{\circ} \mathrm{C}$ in a $5 \% \mathrm{CO}_{2}$-containing atmosphere. Subsequently, $1 \times 10^{4}$ cells were counted for their fluorescence using the FL-2 channel of a FACSCalibur (BD Biosciences, San Jose, CA, USA) and analyzed using CellQuest software (BD Biosciences).

Determination of surface DR4/DR5 expression. The expression levels of DR4 and TDR5 on the cell surface were determined by flow cytometry as previously described (14). Briefly, $5 \times 10^{5}$ cells $/ 100 \mu \mathrm{l}$ were incubated with monoclonal anti-human DR4 and DR5 antibodies or mouse isotypematched control antibodies (R\&D Systems; Minneapolis, MN, USA) for $30 \mathrm{~min}$ at $4^{\circ} \mathrm{C}$. The cells were then centrifuged into a pellet, resuspended in phosphate-buffered saline, and incubated with phycoerythrin-conjugated goat $\mathrm{F}\left(\mathrm{ab}^{\prime}\right)_{2}$ anti-mouse IgG (R\&D Systems) for $30 \mathrm{~min}$ at $4^{\circ} \mathrm{C}$. The fluorescence was measured using the FL-2 channel of the FACSCalibur and analyzed using CellQuest software.

Determination of apoptotic cell death. Apoptotic cell death was quantitatively assessed by double-staining with fluorescein isothiocyanate (FITC)-conjugated Annexin V and propidium iodide (PI) as previously described (13). Briefly, $2 \times 10^{5}$ cells $/ \mathrm{ml}$ in 24-well plates were incubated with the agents to be tested for $20 \mathrm{~h}$ in $10 \% \mathrm{FBS}$-containing medium at $37^{\circ} \mathrm{C}$. Subsequently, the cells were stained with FITC-conjugated Annexin V and PI using a commercially available kit (Annexin V FITC Apoptosis Detection Kit I; BD Pharmingen, San Diego, CA, USA) according to the manufacturer's instructions. The stained cells were evaluated in the FACSCalibur and analyzed using the CellQuest software. Four cellular subpopulations were evaluated: viable cells (Annexin $\mathrm{V}^{-} / \mathrm{PI}^{-}$); early apoptotic cells (Annexin $\mathrm{V}^{+} / \mathrm{PI}^{-}$); late apoptotic cells (Annexin $\mathrm{V}^{+} / \mathrm{PI}^{+}$); and necrotic/damaged cells (Annexin $\mathrm{V}^{-} / \mathrm{PI}^{+}$). Annexin $\mathrm{V}^{+}$ cells were considered to be apoptotic cells.

Measurement of mROS. mROS was measured by flow cytometry using MitoSOX Red [(3,8-phenanthridinediamine, 
5-(6'-triphenyl-phosphoniumhexyl)-5,6-dihydro-6-phenyl); Invitrogen, Carlsbad, CA, USA] as previously described (14). Briefly, $5 \times 10^{5}$ cells suspended in $500 \mu \mathrm{l}$ of HBSS were incubated with the agents to be tested for various times at $37^{\circ} \mathrm{C}$, followed by incubation with $5 \mu \mathrm{M}$ MitoSOX for $15 \mathrm{~min}$ at $37^{\circ} \mathrm{C}$. The cells were then washed, resuspended in HBSS on ice, and centrifuged at $4^{\circ} \mathrm{C}$. The red fluorescence was measured using the FL-2 channel of the FACSCalibur and analyzed using CellQuest software. The data were expressed as $F / F_{0}$, where $F_{0}$ was the fluorescence in unstimulated cells and $\mathrm{F}$ was the fluorescence in stimulated cells.

Measurements of caspase-3/7 activation and mitochondrial membrane potential $(\Delta \psi m)$. Activation of caspase-3/7 and changes in $\Delta \psi \mathrm{m}$ in Jurkat cells were simultaneously measured as previously described (13). Briefly, $2 \times 10^{5}$ cells $/ \mathrm{ml}$ in $24-w e l l$ plates were treated with the agents to be tested for $20 \mathrm{~h}$ in $10 \%$ FBS-containing RPMI-1640 medium at $37^{\circ} \mathrm{C}$, and then stained with the dual sensor MitoCasp ${ }^{\mathrm{TM}}$ (Cell Technology Inc., Mountain View, CA, USA) according to the manufacturer's protocol. Caspase-3/7 activation and $\Delta \psi \mathrm{m}$ were evaluated using the FACSCalibur and the data were analyzed using CellQuest software. Changes in $\Delta \psi \mathrm{m}$ after a short TRAIL treatment were measured using the lipophilic cation JC-1 (5,5',6,6'-tetrachloro-1,1',3, 3'-tetraethylbenzimidazolylcarbocyanine iodide; Molecular Probes, Eugene, OR, USA) as previously described (13). Briefly, $5 \times 10^{5}$ cells $/ 500 \mu 1$ were loaded with $2 \mu \mathrm{M} \mathrm{JC}-1$ at $37^{\circ} \mathrm{C}$ for $15 \mathrm{~min}$, washed, and resuspended in HBSS. After cell stimulation for 2 or $4 \mathrm{~h}$, the green fluorescence (monomeric JC-1) and red fluorescence (J-aggregates) were measured using the FL-1 and FL-2 channels, respectively, of the FACSCalibur and analyzed using CellQuest software.

Measurement of caspase-12 activation. Caspase-12 activation in living cells was measured using the caspase-12 inhibitor ATAD-FMK conjugated to FITC (FITC-ATAD-FMK) as previously described (13). FITC-ATAD-FMK is cellpermeable and non-toxic, and binds irreversibly to active caspase-12, but not inactive caspase-12, in apoptotic cells. Briefly, $2 \times 10^{5}$ cells $/ \mathrm{ml}$ in 24-well plates were treated with the agents to be tested for $20 \mathrm{~h}$ in $10 \% \mathrm{FBS}$-containing medium at $37^{\circ} \mathrm{C}$ and then stained with a CaspGLOW ${ }^{\text {тм }}$ Fluorescein Active Caspase-12 Staining Kit (BioVision) according to the manufacturer's protocol. The fluorescence was determined using the FL-1 channel of the FACSCalibur and analyzed using CellQuest software.

Measurement of cardiolipin oxidation. Oxidation of cardiolipin was measured by flow cytometry using the fluorescent dye 10- $N$-nonyl acridine orange (NAO; Invitrogen), which binds to non-oxidized cardiolipin, but not to oxidized cardiolipin, as previously described (14). Briefly, $5 \times 10^{5}$ cells suspended in $500 \mu \mathrm{l}$ of HBSS were incubated with the agents to be tested for $4 \mathrm{~h}$ at $37^{\circ} \mathrm{C}$, and then incubated with $100 \mathrm{nM}$ NAO for $15 \mathrm{~min}$ at $37^{\circ} \mathrm{C}$. The harvested cells were washed and resuspended in HBSS on ice. Their fluorescence was measured using the FL-1 channel of the FACSCalibur and analyzed using CellQuest software. The data were expressed as $F / F_{0}$, where $F_{0}$ was the fluorescence in unstimulated cells and $F$ was the fluorescence in stimulated cells.
Western blot analysis. Western blot analysis was performed as previously described (14). Briefly, $1 \times 10^{6}$ cells $/ \mathrm{ml}$ in 6 -well plates were treated with the agents to be tested for $20 \mathrm{~h}$ in $10 \%$ FBS-containing medium at $37^{\circ} \mathrm{C}$, washed, and lysed with SDS-sample buffer. Whole cell lysates (30 $\mu \mathrm{g}$ protein) were subjected to SDS-PAGE using a $10 \%$ separation gel under reducing conditions and then transferred to polyvinylidene difluoride membranes (Millipore, Bedford, MA, USA). The membranes were incubated with BlockAce (Dainippon Sumitomo Pharma, Osaka, Japan) for $1 \mathrm{~h}$ at room temperature, washed, incubated with polyclonal antibodies against X-box-binding protein (XBP)-1 or caspase-3 (Cell Signaling Technology Japan, Tokyo, Japan) overnight at $4^{\circ} \mathrm{C}$, washed again, and incubated with horseradish peroxidase-conjugated species-specific anti-rabbit Ig (GE Healthcare Japan, Tokyo, Japan) for $1 \mathrm{~h}$ at room temperature. After extensive washing, the immunoreactive proteins on the membranes were detected using an Enhanced ChemiLuminescence (ECL) Prime Kit (GE Healthcare Japan) according to the manufacturer's recommendations. To verify equal loading, the membranes were re-probed with a monoclonal anti-GAPDH antibody (Santa Cruz Biotechnology). The signal intensities were quantified relative to the GAPDH signal intensity using NIH Image software (NIH, Bethesda, MD, USA).

Statistical analysis. The statistical significance of differences among multiple groups was analyzed by one-way analysis of variance (ANOVA) followed by the Tukey's test. The significance of differences between two individual groups was analyzed by Student's t-test. Values of $\mathrm{P}<0.05$ were considered to indicate statistical significance.

\section{Results}

$K^{+}$-mediated depolarization potentiates TRAIL-induced apoptosis in human tumor cells with different origins. To determine whether the modulation of TRAIL-induced apoptosis by membrane-depolarizing agents is a general feature of tumor cells with different origins, we examined the effect of high $\mathrm{K}^{+}$ loading on TRAIL-induced apoptosis in Jurkat leukemia cells. The cells were treated with TRAIL in the presence or absence of $50 \mathrm{mM} \mathrm{KCl}$ for $20 \mathrm{~h}$, and then double-stained with Annexin V/PI. TRAIL at concentrations of $\geq 6.3 \mathrm{ng} / \mathrm{ml}$ increased apoptotic (Annexin $\mathrm{V}^{+} / \mathrm{PI}^{-}$) cells, but not necrotic (Annexin $\mathrm{V}^{-} / \mathrm{PI}^{+}$) cells, in a dose-dependent manner. $\mathrm{KCl}$ alone caused minimal cell death, but significantly potentiated TRAIL-induced apoptosis (Fig. 1A). Measurement of membrane potential changes using bis-oxonol showed that $\mathrm{KCl}$ induced rapid (within $5 \mathrm{~min}$ ) membrane depolarization that peaked at $2 \mathrm{~h}$ and declined thereafter (Fig. 1B). TRAIL evoked robust depolarization in a dose- and time-dependent manner, but the effect was observed after a considerable time lag. The effect was initially observed at $2 \mathrm{~h}$ for $100 \mathrm{ng} / \mathrm{ml}$ TRAIL (1.3-fold) and developed during another $2 \mathrm{~h}$ to reach 1.3- and 1.6-fold for 25 and $100 \mathrm{ng} / \mathrm{ml}$ TRAIL, respectively (Fig. 1B). $\mathrm{K}^{+}$loading also enhanced TRAIL-induced apoptosis, but not necrosis, in A549 lung cancer cells (Fig. 1C). In contrast, TRAIL and $\mathrm{KCl}$ alone or in combination caused minimal cell death in WI-38-40 fibroblasts despite their substantial DR5 expression (Fig. 1D). Collectively, these findings show that $\mathrm{K}^{+}$-mediated depolarization potentiates 

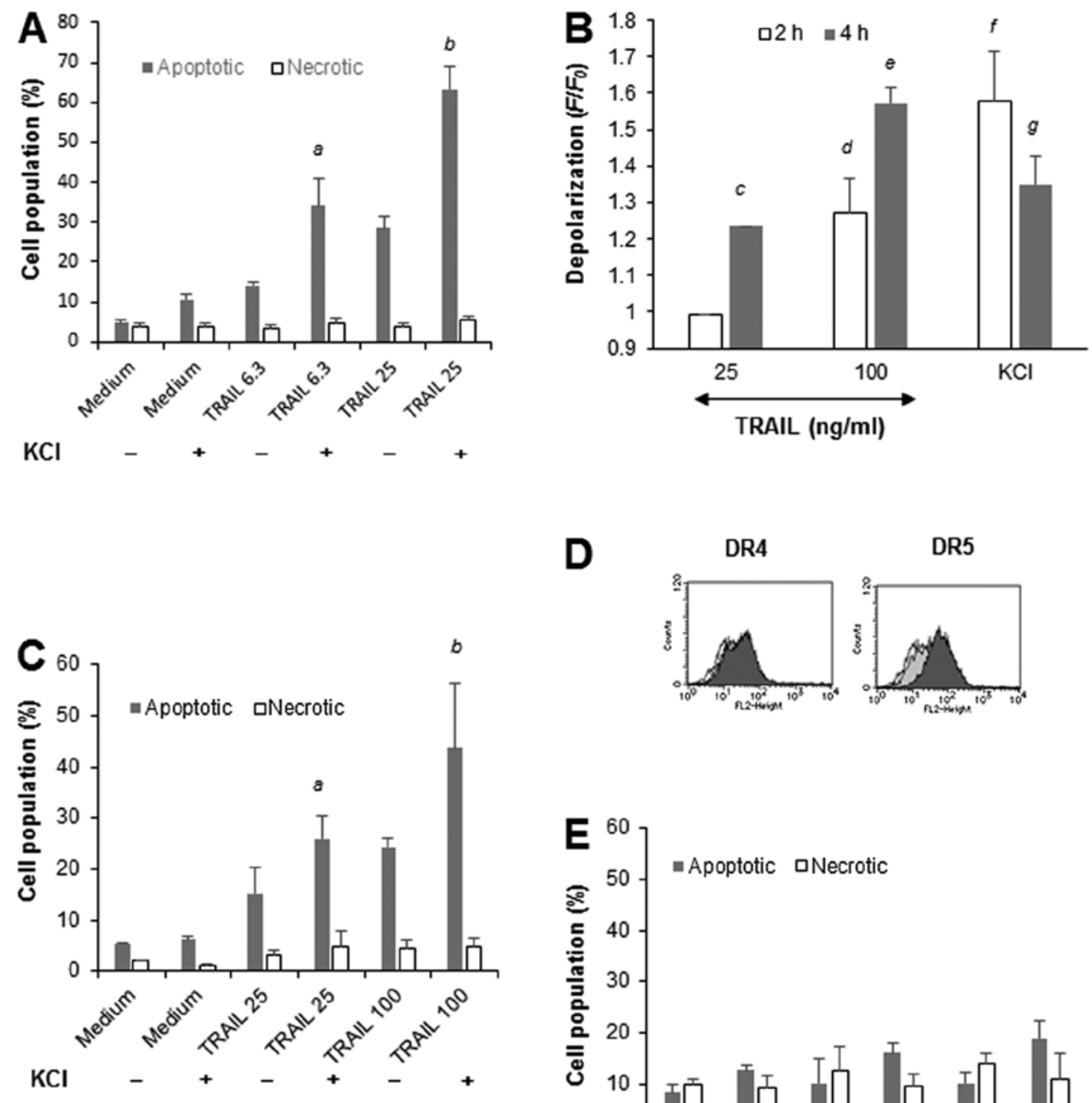

D

DR4
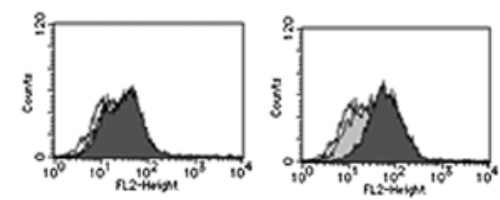

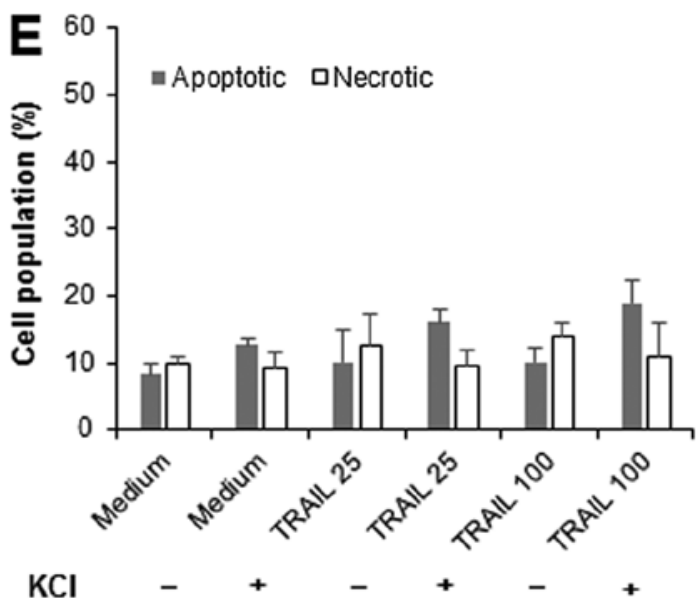

Figure $1 . \mathrm{K}^{+}$-mediated depolarization potentiates TRAIL-induced apoptosis in human tumor cells with different origins, but not in non-transformed cells (A) Jurkat cells were treated with TRAIL at the indicated concentrations in the presence or absence of $50 \mathrm{mM} \mathrm{KCl}$ for $20 \mathrm{~h}$, stained with Annexin V-FITC and PI, and analyzed by flow cytometry. Annexin $\mathrm{V}^{+}$cells and Annexin $\mathrm{V}^{-} / \mathrm{PI}^{+}$cells were considered to be apoptotic cells and necrotic cells, respectively. The data represent means $\pm \mathrm{SE}(\mathrm{n}=4)$. Letters a and $\mathrm{b}$, indicate significance vs TRAIL alone. (B) Jurkat cells that had been loaded with bis-oxonol were treated with 25 or $100 \mathrm{ng} / \mathrm{ml}$ TRAIL or $\mathrm{KCl}$ for $4 \mathrm{~h}$, and analyzed for their fluorescence by flow cytometry. The data are expressed as $\mathrm{F} / \mathrm{F}_{0}$, where $\mathrm{F}_{0}$ is the fluorescence in unstimulated cells and $\mathrm{F}$ is the fluorescence in stimulated cells, and represent means $\pm \mathrm{SE}(\mathrm{n}=4)$. Letters c to $\mathrm{g}$, indicate significance vs control. (C) A549 lung cancer cells and (E) WI-38-40 cells were treated with TRAIL at the indicated concentrations in the presence or absence of $\mathrm{KCl}$ for $20 \mathrm{~h}$, stained with Annexin V-FITC and PI, and analyzed by flow cytometry. Annexin $\mathrm{V}^{+}$cells and Annexin $\mathrm{V}^{-} / \mathrm{PI}^{+}$cells were considered to be apoptotic cells and necrotic cells, respectively. The data represent means \pm SE ( $n=3$ and $n=4$, respectively). Letters a and b, indicate significance vs TRAIL alone. (D) Surface DR4/DR5 expression levels in WI-38-40 cells. The cells were analyzed for their expression of DR4 and DR5 levels by indirect immunofluorescence and flow cytometry. In the panels, the black lines represent specific staining, the gray lines represent IgG isotype control staining, and the solid lines represent the unstained control.

TRAIL-induced apoptosis in human tumor cells with different origins, but not in non-transformed cells.

$K_{\text {ATP }}$ inhibitors specifically potentiate TRAIL-induced apoptosis in human tumor cells with different origins. To verify the role of depolarization, we examined the effects of the $\mathrm{K}_{\mathrm{ATP}}$ channel inhibitors GLB and U37. As shown in Fig. 2A and B, each drug markedly potentiated the TRAIL-induced apoptosis in Jurkat cells, although they caused minimal cell death on their own. In contrast, TEA, which mainly inhibits voltage-dependent potassium $\left(\mathrm{K}_{\mathrm{v}}\right)$ channel and $\mathrm{Ca}^{2+}$-dependent potassium $\left(\mathrm{K}_{\mathrm{Ca}}\right)$ channels, had no such effect (Fig. 2B), suggesting a specific role of $\mathrm{K}_{\mathrm{ATP}}$ channels in the potentiation. In support of this view, treatment of the cells with the $\mathrm{K}_{\mathrm{v}}$ channel-specific inhibitor 

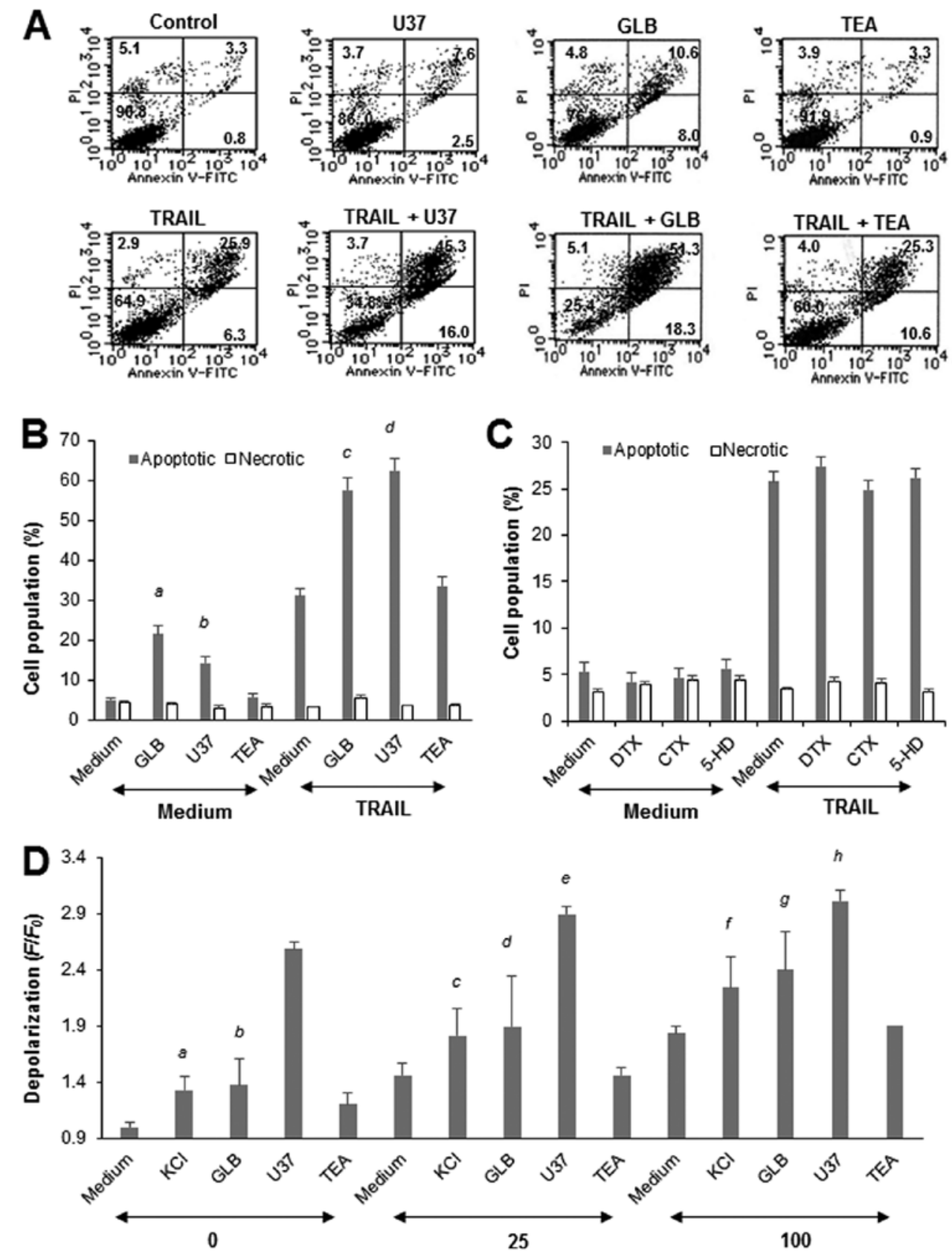

Figure 2. $\mathrm{K}_{\text {ATP }}$ channel inhibitors specifically potentiate TRAIL-induced apoptosis in Jurkat cells. (A and B) Jurkat cells were treated with $25 \mathrm{ng} / \mathrm{ml}$ TRAIL and $100 \mu \mathrm{M}$ U37, GLB or TEA alone or in combination for $20 \mathrm{~h}$, stained with Annexin V-FITC and PI, and analyzed by flow cytometry. Annexin $\mathrm{V}^{+}$cells and Annexin $\mathrm{V} / \mathrm{PI}^{+}$cells were considered to be apoptotic cells and necrotic cells, respectively. (A) A typical histogram is shown. (B) The data represent means $\pm \mathrm{SE}$ $(\mathrm{n}=4)$. Letters a to $\mathrm{d}$ indicate significance vs control. (C) The cells were treated with $25 \mathrm{ng} / \mathrm{ml}$ TRAIL and $100 \mu \mathrm{M}$ DTX, CTX or HD alone or in combination for $24 \mathrm{~h}$, and apoptotic cell death was measured by flow cytometry using Annexin V-FITC and PI staining. Annexin $\mathrm{V}^{+}$cells and Annexin $\mathrm{V}^{-} / \mathrm{PI}^{+}$cells were considered to be apoptotic cells and necrotic cells, respectively. The data represent means \pm SE ( $\mathrm{n}=3$ and $\mathrm{n}=4$, respectively). (D) Cells that had been loaded with bis-oxonol were treated with TRAIL at the indicated concentrations and $\mathrm{KCl}, \mathrm{U} 37$, GLB or TEA alone or in combination for $4 \mathrm{~h}$, and analyzed for their fluorescence by flow cytometry. The data are expressed as $F / F_{0}$, where $F_{0}$ is the fluorescence in unstimulated cells and $F$ is the fluorescence in stimulated cells, and represent means $\pm \mathrm{SE}(\mathrm{n}=4)$. Letters a to $\mathrm{h}$ indicate significance vs control.

DTX and $\mathrm{K}_{\mathrm{Ca}}$ channel-specific inhibitor CTX for $20 \mathrm{~h}$ had minimal effects on the apoptosis (Fig. 2C). The mitochondrial $\mathrm{K}_{\text {АTP }}$ channel inhibitor HD had no effect either. All of these drugs had minimal effects on the apoptosis for at least another $48 \mathrm{~h}$ (data not shown). As shown in Fig. 2D, GLB or U37 alone increased the depolarization by 1.4- and 2.6-fold, respectively, and higher degrees of depolarization were observed in the cells treated with TRAIL in the presence of each drug compared with the cells treated with TRAIL alone. However, unlike the case for apoptosis, their effects were less than additive. In contrast, TEA induced marginal depolarization (maximum of 1.2-fold) and had a minimal effect on TRAIL-induced depolarization. GLB and U37 also potentiated the TRAIL-induced apoptosis in A549 cells, while TEA, DTX and CTX had no such effects (data not shown). Again, GLB and U37 alone or in combination with TRAIL had minimal effects on the survival of WI-38-40 
A

DR4

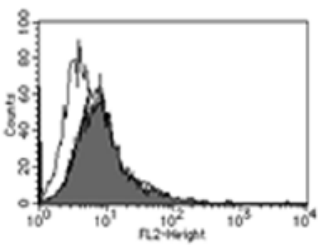

DR5

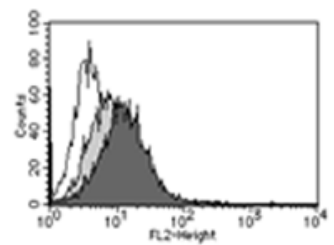

B

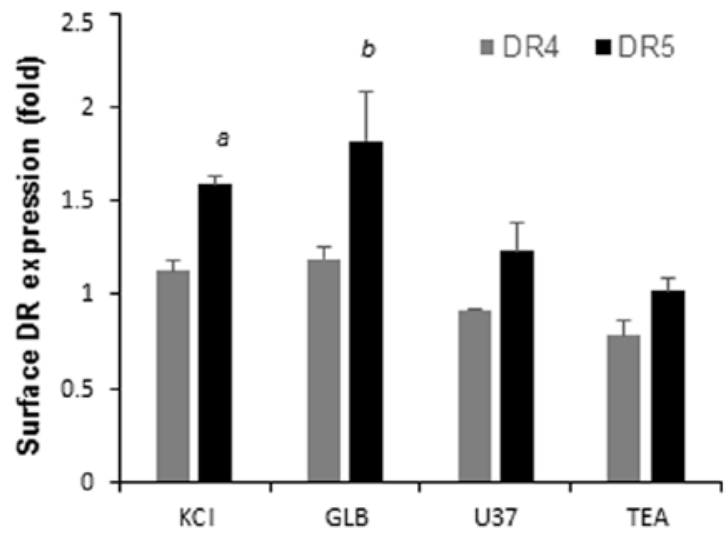

Figure 3. Membrane-depolarizing agents upregulate surface DR5 expression in Jurkat cells. (A and B) Jurkat cells were treated with KCl, U37, GLB or TEA for $20 \mathrm{~h}$, and then incubated with anti-DR4, anti-DR5 or isotype-matched antibodies for $30 \mathrm{~min}$ at $4^{\circ} \mathrm{C}$. The cells were then centrifuged into a pellet, resuspended in phosphate-buffered saline, and incubated with phycoerythrin-conjugated goat $\mathrm{F}\left(\mathrm{ab}^{\prime}\right)_{2}$ anti-mouse $\operatorname{IgG}$ for $30 \mathrm{~min}$ at $4^{\circ} \mathrm{C}$. The fluorescence was measured using the FL-2 channel of the FACSCalibur and analyzed using CellQuest software. (A) A representative histogram of KCl-treated cells is shown. In the panels, the light and dark gray lines represent specific staining in control and KCl-treated cells, respectively, and the solid lines represent the unstained control. (B) The data represent means $\pm \mathrm{SE}(\mathrm{n}=3)$. Letters a and $\mathrm{b}$ indicate significance vs control.

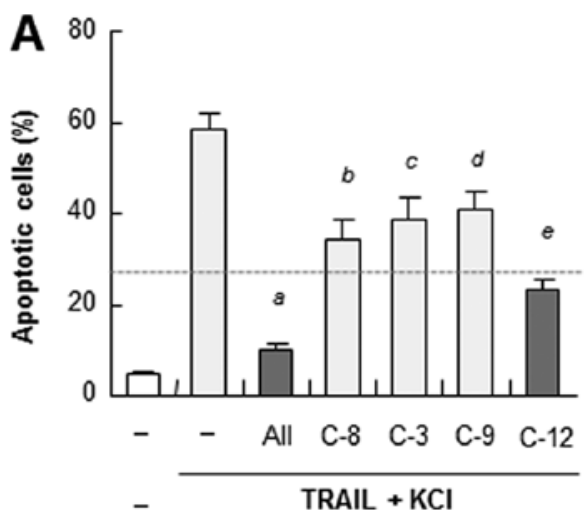

C
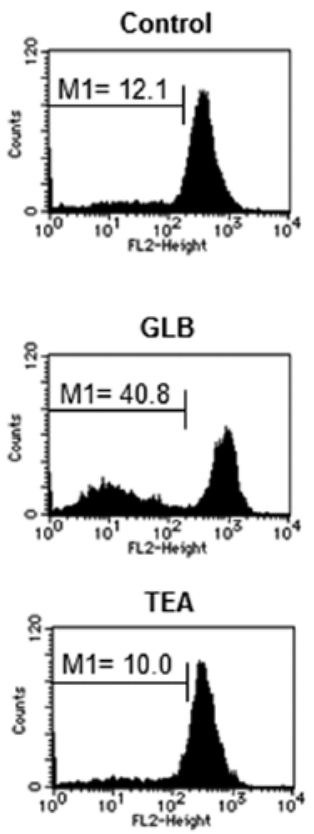

TRAIL + TEA

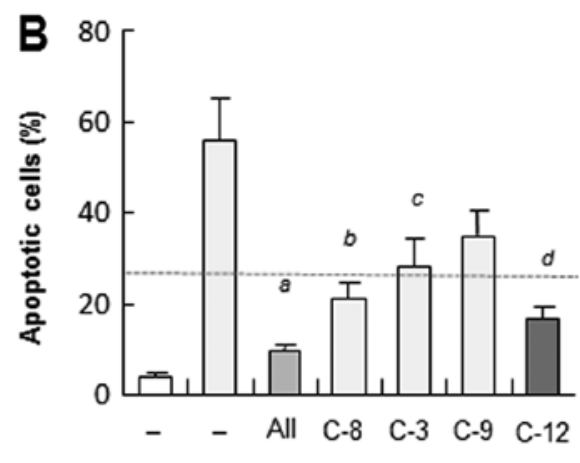

TRAIL + U37
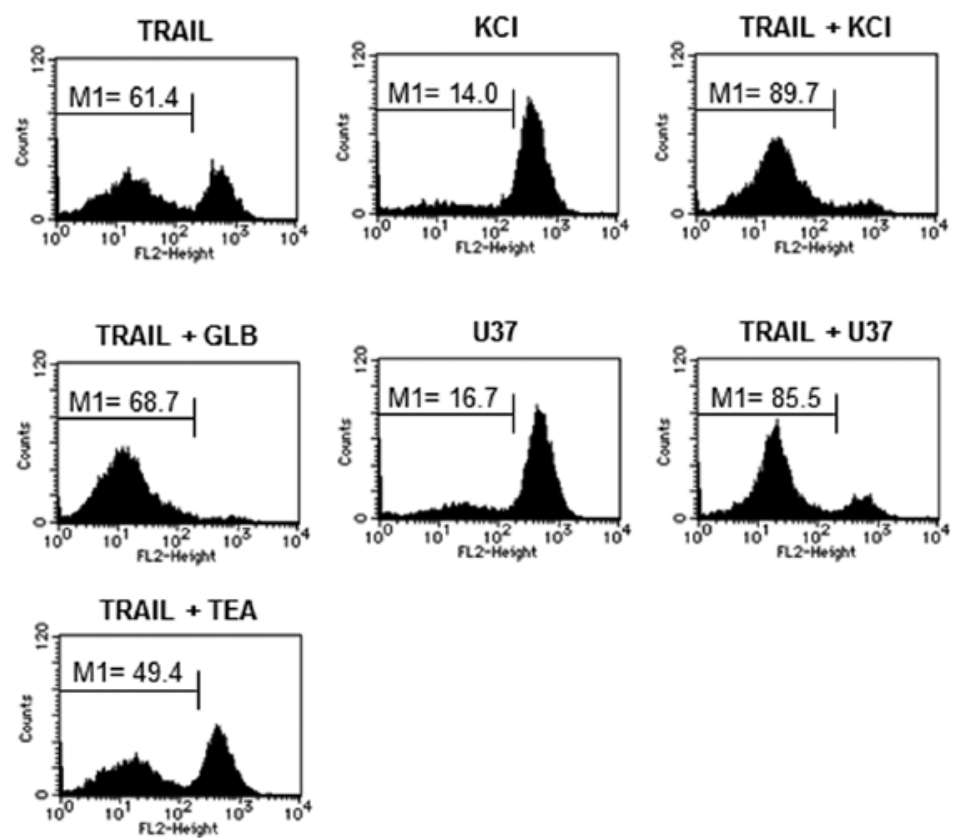

Figure 4. Membrane-depolarizing agents potentiate the mitochondrial death pathway in Jurkat cells. (A and B) Jurkat cells were treated with $25 \mathrm{ng} / \mathrm{ml}$ TRAIL and $\mathrm{KCl}$ or $\mathrm{U} 37$ alone or in combination in the presence or absence of $10 \mu \mathrm{M}$ z-VAD-FMK (All), z-IETD-FMK (C-8), z-DEVD-FMK (C-3), z-LEHD-FMK (C-9) or z-ATAD-FMK (C-12) for $20 \mathrm{~h}$, and apoptotic cell death was measured by flow cytometry using Annexin V-FITC and PI staining. The data represent means \pm SE $(n=4)$. Letters a to e in (A) and a to $d$ in (B), indicate significance vs control without inhibitors. (C) The cells were treated with TRAIL and KCl, U37, GLB or TEA alone or in combination, and MMP depolarization was determined by flow cytometry $(\mathrm{n}=3)$. 


\section{Caspase-3/7}
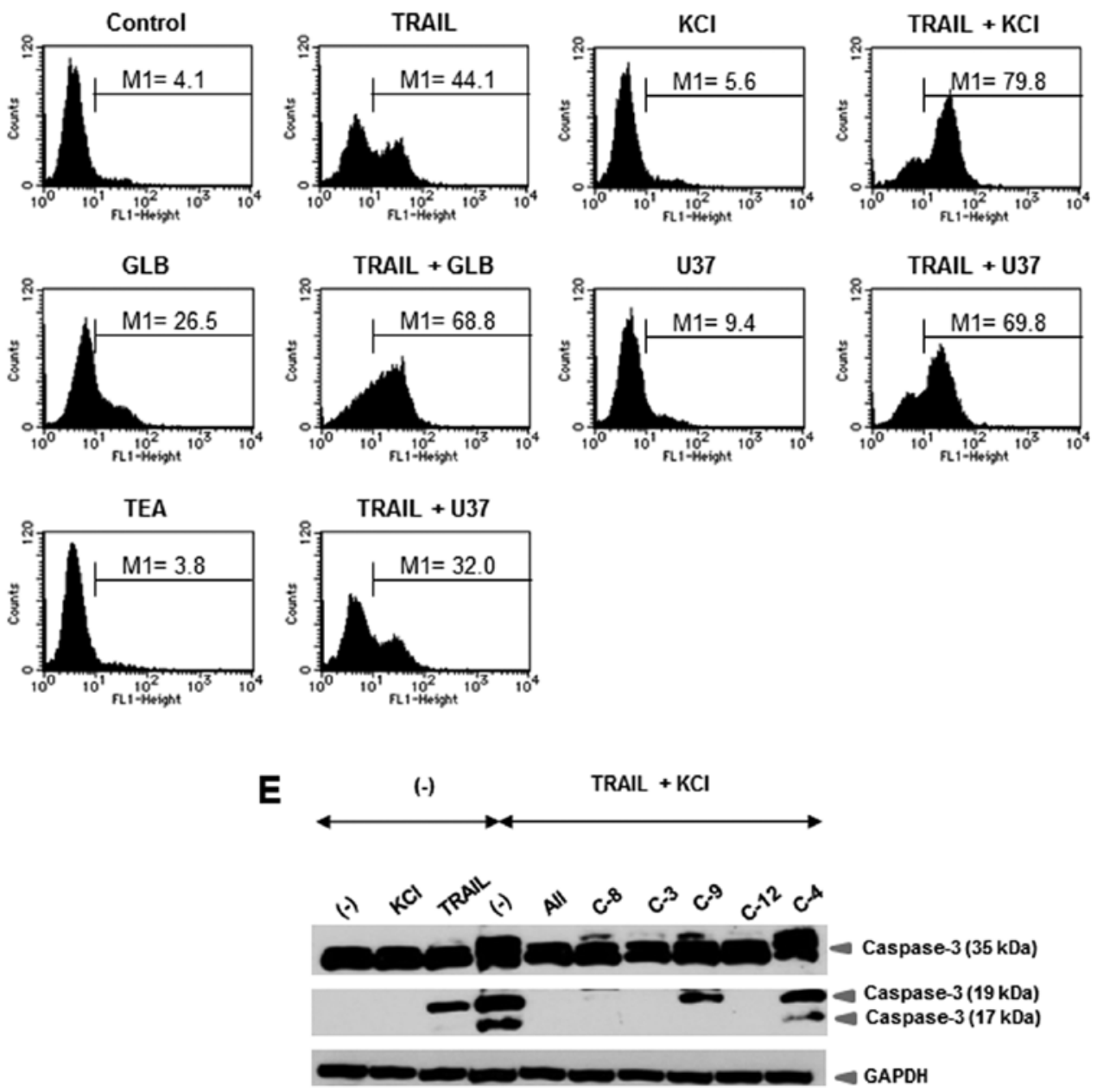

Figure 4. Continued.(D) The cells were treated with TRAIL and KCl, U37, GLB or TEA alone or in combination, and caspase-3/7 activation was determined by flow cytometry $(\mathrm{n}=3)$. (E) The cells were treated with TRAIL and $\mathrm{KCl}$ alone or in combination, in the presence or absence of $\mathrm{z}$-VAD-FMK (All), $\mathrm{z}$-IETD-FMK (C-8), z-DEVD-FMK (C-3), z-LEHD-FMK (C-9), z-ATAD-FMK (C-12) or z-LEVD-FMK for $20 \mathrm{~h}$. The cells were then washed, lysed with SDS-sample buffer and analyzed for their contents of full-length and cleaved caspase-12 by western blot analysis with a specific antibody. To verify equal loading, the blots were re-probed with an anti-GAPDH antibody.

fibroblasts (data not shown). These results show that $\mathrm{K}_{\mathrm{ATP}}$ channel inhibitors specifically potentiate TRAIL-induced apoptosis in human tumor cells with different origins, but not in non-transformed cells.

Potentiation of apoptosis is associated with upregulation of cell surface DR5 expression. Since amplification of TRAIL-induced apoptosis is often associated with upregulated expression of DR5 (15-17), we examined the effects of the membrane-depolarizing agents on the expressions of DR4 and DR5. Jurkat cells were exposed to $\mathrm{KCl}$ for various times and analyzed for their expression levels of DR4 and DR5 on the cell surface using specific antibodies. Until $4 \mathrm{~h}$ after $\mathrm{K}^{+}$loading, the cell surface DR4 and DR5 expression levels were minimally changed compared with their basal levels. On the other hand, $\mathrm{K}^{+}$loading for a longer time $(20 \mathrm{~h})$ increased the cell surface DR5 expression by 1.6 -fold, but minimally increased the cell surface DR4 expression (Fig. 3A). Similarly, GLB and U37 increased the DR5 expression levels by 1.8- and 1.2-fold, respectively, while the former, but not the latter, marginally increased the DR4 expression (maximum of 1.2-fold). In contrast, TEA had minimal effects on the DR4 and DR5 expression levels (Fig. 3A). These results show that the potentiation of apoptosis is associated with upregulation of cell surface DR5 expression.

Membrane-depolarizing agents potentiate the mitochondrial death pathway. We previously showed that TRAIL-induced apoptosis in Jurkat cells and A375 cells was caspasedependent $(13,14)$. Therefore, an array of caspase-specific inhibitors $(10 \mu \mathrm{M})$ were tested for their abilities to affect the potentiation of apoptosis. The pan-caspase inhibitor z-VAD-FMK almost completely blocked apoptosis. The caspase-8-specific inhibitor z-IETD-FMK, caspase-9-specific inhibitor z-LEHD-FMK, and/or caspase-3/7-specific inhibitor z-DEVD-FMK significantly abolished the effects of $\mathrm{KCl}$ or U37 (Fig. 4A and B), indicating that both the extrinsic and intrinsic (mitochondrial) apoptotic pathways are involved in the potentiation. Consistent with the role of caspase-12 in the TRAIL-induced apoptosis in Jurkat cells (14), the 
A
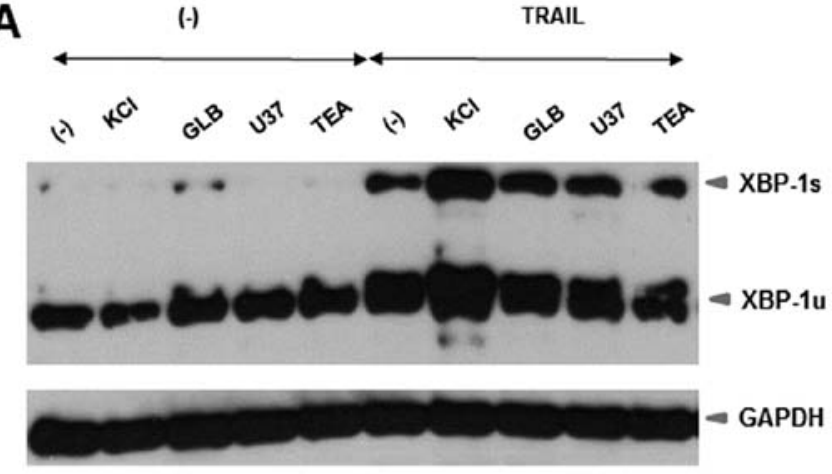

B

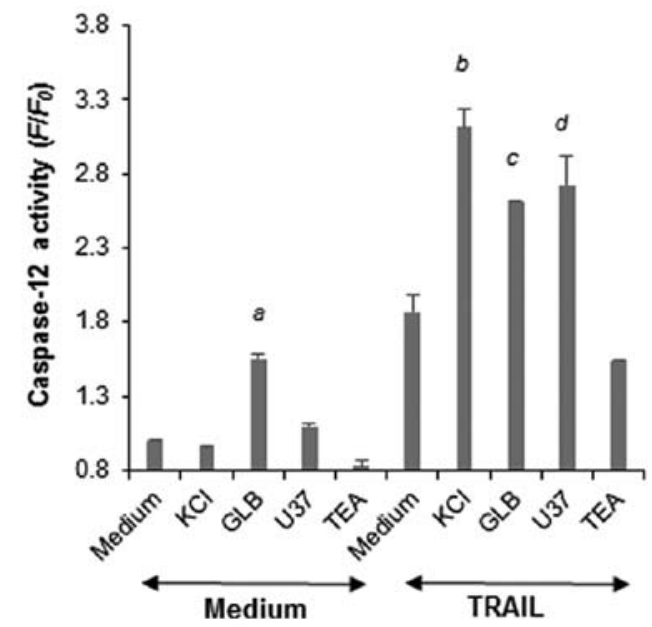

Figure 5. Membrane-depolarizing agents potentiate ER stress responses in Jurkat cells. (A) Jurkat cells were treated with $25 \mathrm{ng} / \mathrm{ml}$ TRAIL and $\mathrm{KCl}$, U37, GLB or TEA alone or in combination for $20 \mathrm{~h}$, and analyzed for their contents of XBP-1 by western blot analysis with a specific antibody. To verify equal loading, the blots were re-probed with an anti-GAPDH antibody $(n=3)$. (B) The cells were treated as described above, and measured for their caspase-12 activity by flow cytometry using FITC-ATAD-FMK. The data are expressed as $F / F_{0}$, where $\mathrm{F}_{0}$ is the fluorescence in unstimulated cells and $\mathrm{F}$ is the fluorescence in stimulated cells, and represent means \pm SE $(n=3)$. Letter a indicates significance vs control; and letters b, $c$ and d, indicate significance vs TRAIL alone.

caspase-12-specific inhibitor z-ATAD-FMK also completely abrogated the effects of $\mathrm{KCl}$ or U37 (Fig. 4A and B). In support of the role of the mitochondrial death pathway, TRAIL induced robust mitochondrial membrane potential depolarization and activation of caspase-3/7. The MMP depolarization and caspase-3/7 activation were markedly potentiated by $\mathrm{KCl}$ or $\mathrm{K}_{\mathrm{ATP}}$ channel inhibitors, although each drug alone, except for GLB, had minimal effects on the two events (Fig. 4C and D). Consistent with the role of caspase-3, TRAIL induced robust caspase- 3 cleavage, as shown by the appearance of a truncated form, i.e., caspase-3 (19 kDa) (Fig. 4E). $\mathrm{KCl}$ potentiated the effect, resulting in the new appearance of an even smaller form of caspase-3 (17 kDa). The appearance of caspase-3 (17 kDa) was completely abrogated by the pan-caspase inhibitor and the specific inhibitors of caspase- $8,-9,-3$ and-12, but not by that of caspase- 4 . The caspase- 8 and caspase-12 inhibitors also abolished the appearance of caspase-3 (19 kDa), while the caspase-9 inhibitor did not (Fig. 4E). These results show that in the presence or absence of depolarization, TRAIL induces caspase- 3 cleavage in a different manner.
Membrane-depolarizing agents potentiate ER stress responses. We previously showed that TRAIL induced ER stress in Jurkat cells (14). The ER-mediated death pathway is another pathway for apoptosis that is independent of the extrinsic and intrinsic pathways (18-20). To examine the possible role of this pathway, we analyzed the effects of the membrane-depolarizing drugs on XBP-1 activation, a cellular response to ER stress. Western blot analyses revealed that TRAIL dose-dependently increased the expression levels of both the inactive unspliced form of XBP-1 (XBP-1u) and the active spliced form of XBP-1 (XBP-1s) by about 2-fold, indicating activation of XBP-1. Although each drug alone caused minimal activation of XBP-1, $\mathrm{KCl}$ and $\mathrm{K}_{\text {ATP }}$ channel inhibitors, but not TEA, markedly potentiated the effects of TRAIL (Fig. 5A). Next, we examined the effects of the membrane-depolarizing agents on TRAIL-induced caspase-12 activation. The activation of caspase-12 was evaluated by measuring the conversion of a cell-permeable substrate, FITC-ATAD-FMK. As shown in Fig. 5B, each drug alone except for GLB, caused minimal caspase-12 activation, while $\mathrm{KCl}$ and $\mathrm{K}_{\mathrm{ATP}}$ channel inhibitors, but not TEA, markedly potentiated TRAIL-induced caspase-12 activation. Taken together, these results show that the membrane-depolarizing agents potentiate ER stress responses including caspase-12 activation.

Functional coupling of mROS and depolarization during TRAIL-induced apoptosis. Previously we showed that TRAIL treatment resulted in mROS accumulation that mediated mitochondrial and ER dysfunctions during TRAIL-induced apoptosis (14). Therefore, we investigated the possible role of mROS in the potentiation of apoptosis by depolarization. To explore the possibility that mROS mediate the depolarization, we examined the effects of membrane-depolarizing drugs on mROS generation. MitoSOX Red localizes to mitochondria and serves as a fluoroprobe for selective detection of superoxide in these organelles $(21,22)$. TRAIL induced mROS generation in a dose-dependent manner, and $\mathrm{KCl}$ or U37 markedly potentiated this effect, while each drug alone minimally increased the generation (Fig. 6A). Oxidation of cardiolipin serves as another biochemical hallmark of mitochondrial oxidative stress, because this phospholipid exists in association with cytochrome $c$ on the outer surface of the inner mitochondrial membrane. Because the fluorescent dye NAO binds to the non-oxidized form, but not to the oxidized form, of cardiolipin, independently of $\Delta \psi \mathrm{m}$, measurements of NAO fluorescence enable us to monitor the oxidation of cardiolipin in mitochondria (23). Consistent with our previous study (14), TRAIL treatment resulted in a dose-dependent decrease in NAO fluorescence, indicating the induction of cardiolipin oxidation. Agonistic antibodies against DR4 and DR5, which trigger the formation of multimeric complexes containing only specific TRAIL-Rs (24-26) also induced robust cardiolipin oxidation in a dose-dependent manner (Fig. 6B), indicating that this oxidation is mediated by DR4/DR5. Collectively, these results show that TRAIL induces mROS accumulation and that depolarization potentiates this process. Mitochondria serve a major source of ROS under physiological conditions and generate large amounts of ROS when their metabolism is impaired under pathological conditions. Indeed, we previously showed that mitochondrial metabolic inhibitors, such as the complex I inhibitor ROT, complex III inhibitor AM 

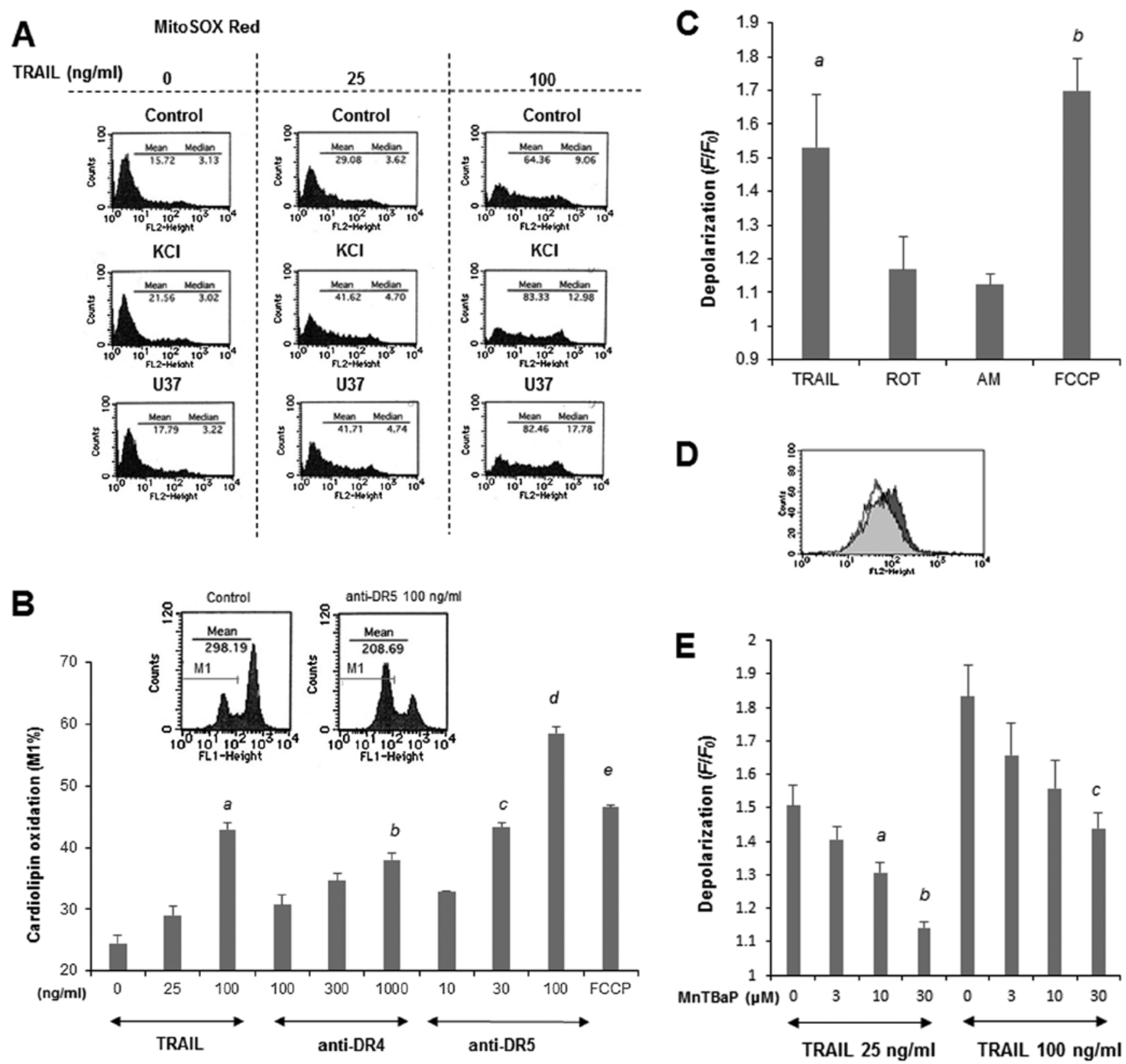

Figure 6. Functional coupling of mitochondrial ROS and depolarization in Jurkat cells. (A) Jurkat cells were treated with $25 \mathrm{or} 100 \mathrm{ng} / \mathrm{ml} \mathrm{TRAIL}$ and KCl or U37 alone or in combination for $4 \mathrm{~h}$, and then incubated with $5 \mu \mathrm{M}$ MitoSOX Red for $15 \mathrm{~min}$ at $37^{\circ} \mathrm{C}$. After washing, the cells were immediately resuspended in HBSS on ice. The fluorescence was measured using the FL-1 or FL-2 channel of the FACSCalibur and analysed using the CellQuest software. A representative histogram is shown $(\mathrm{n}=3)$. (B) The cells were loaded with $100 \mathrm{nM} \mathrm{NAO}$ for $15 \mathrm{~min}$ at $37^{\circ} \mathrm{C}$, washed and resuspended in HBSS. The NAO-loaded cells were treated with TRAIL, anti-DR4 or anti-DR5 antibodies at the indicated concentrations or $5 \mu \mathrm{M} \mathrm{FCCP} \mathrm{at} 37^{\circ} \mathrm{C}$ for $4 \mathrm{~h}$. After washing, the cells were immediately resuspended in HBSS on ice. The NAO fluorescence was measured using the FL-1 channel of the FACSCalibur. Representative histograms are shown in the upper panel. The data shown are expressed as percentages of the cell population with cardiolipin oxidation (M1 in the upper panel) relative to the whole cell population (set at $100 \%$ ), and represent means $\pm \mathrm{SE}(\mathrm{n}=3$ ). Letters a to e, indicate statistical significance vs control. (C) Cells loaded with bis-oxonol were treated with $100 \mathrm{ng} / \mathrm{ml}$ TRAIL, $5 \mu \mathrm{M}$ ROT, $5 \mu \mathrm{g} / \mathrm{ml}$ AM or $5 \mu \mathrm{M} \mathrm{FCCP}$ for $4 \mathrm{~h}$, and analyzed for their fluorescence by flow cytometry. The data are expressed as F/ $\mathrm{F}_{0}$, where $\mathrm{F}_{0}$ is the fluorescence in unstimulated cells and $\mathrm{F}$ is the fluorescence in stimulated cells, and represent means $\pm \mathrm{SE}(\mathrm{n}=2-6)$. Letters a and $\mathrm{b}$, indicate statistical significance vs control. (D) Cells loaded with bis-oxonol were treated with 25 or $100 \mathrm{ng} / \mathrm{ml}$ TRAIL in the presence or absence of MnTBaP at the indicated concentrations, and analyzed for their fluorescence by flow cytometry. A representative histogram is shown in the upper panel. In the panel, the dark gray lines represent the fluorescence of $25 \mathrm{ng} / \mathrm{ml}$ TRAIL alone and the light gray lines represents the fluorescence of TRAIL in the presence of $30 \mu \mathrm{M} \mathrm{MnTBaP,}$ while the solid lines represent the fluorescence of the medium control. (E) Cells loaded with bis-oxonol were treated with $25 \mathrm{or} 100 \mathrm{ng} / \mathrm{ml}$ or $5 \mu \mathrm{M} \mathrm{FCCP}$ in the presence or absence of $\mathrm{MnTBaP}$ at the indicated concentrations, and analyzed for their fluorescence by flow cytometry. The data are expressed as $F / F_{0}$, where $F_{0}$ is the fluorescence in unstimulated cells and $F$ is the fluorescence in stimulated cells, and represent means $\pm \mathrm{SE}(\mathrm{n}=4)$. Letters a to $\mathrm{c}$ indicate statistical significance vs TRAIL alone.

and mitochondrial uncoupling agent FCCP, considerably increased the mROS levels in Jurkat cells, thereby enhancing the TRAIL-induced mitochondrial and ER dysfunctions and apoptosis (14). In agreement with these previous observa- tions, FCCP considerably increased the cardiolipin oxidation (Fig. 6B). To obtain further evidence for the functional coupling between mROS and depolarization, we examined the ability of these metabolic inhibitors to provoke depolarization. As 
expected, among these metabolic inhibitors, FCCP was the most potent at provoking depolarization (Fig. 6C). This effect (1.7-fold) was comparable to that of $100 \mathrm{ng} / \mathrm{ml}$ of TRAIL, while ROT and AM had marginal effects (maximum of 1.2-fold), in parallel with their effects on MitoSOX Red signals (14). The coincident induction of depolarization and mROS led us to hypothesize the presence of another biochemical consequence between them. i.e., that mROS mediate the depolarization. To test this hypothesis, we examined the effect of MnTBaP on the TRAIL-induced depolarization, since this antioxidant can block TRAIL-induced mROS generation in the cells (14). As shown in Fig. 6D, treatment with non-toxic concentrations of MnTBaP ranging from 3 to $30 \mu \mathrm{M}$ dose-dependently reduced the TRAIL-induced depolarization. The effectiveness of this antioxidant varied considerably depending on the concentration of TRAIL applied. MnTBaP $(30 \mu \mathrm{M})$ almost completely reduced the depolarization induced by $25 \mathrm{ng} / \mathrm{ml}$ TRAIL, while it reduced the depolarization induced by $100 \mathrm{ng} / \mathrm{ml}$ TRAIL by a maximum of $50 \%$ (Fig. 6D). Consequently, the levels of depolarization became comparable to those induced by $25 \mathrm{ng} / \mathrm{ml}$ TRAIL. On the other hand, MnTBaP reduced the depolarization induced by FCCP by only $20 \%$ even when used at the highest concentration. Collectively, these findings show a closed functional coupling of mROS and depolarization during TRAIL-induced apoptosis.

Role of $m R O S$ in the potentiation of TRAIL-induced apoptosis by depolarization in human A375 melanoma cells. Since depolarization potentiates TRAIL-induced apoptosis in several human melanoma cell lines (13), we investigated whether similar biochemical pathways involving mROS underlie this potentiation using A375 melanoma cells as a model. First, we examined the effects of the membrane-depolarizing drugs on the cell surface DR expression levels. Until $4 \mathrm{~h}$ after exposure to each drug, the DR4 and DR5 expression levels were minimally changed compared with their basal levels. On the other hand, treatment with $\mathrm{KCl}$ or $\mathrm{U} 37$ for $20 \mathrm{~h}$ increased the DR5 expression levels by 1.3 and 1.6-fold, respectively, while minimally increasing the DR4 expression levels (Fig. 7A). In contrast, GLB and TEA had minimal effects on the DR4 and DR5 expression levels, in parallel with their ineffectiveness at potentiating apoptosis (13). Similar to Jurkat cells (14), ROT, AM and FCCP increased the mROS levels. Among these agents, AM was the most powerful (7.8-fold) and the effects of ROT and FCCP were comparable (1.9- and 2.1-fold, respectively). These drugs also potentiated TRAIL-induced apoptosis in the cells (Fig. 7B). For $25 \mathrm{ng} / \mathrm{ml}$ TRAIL, necrotic cell death was also substantially increased. Finally, we examined whether these mitochondrial metabolic inhibitors affected the cell membrane potential. AM and FCCP, but not ROT, alone caused robust depolarization (1.2-1.4-fold), and potentiated TRAIL-induced depolarization (Fig. 7C), indicating that mROS accumulation potentiates depolarization. Conversely, MnTBaP treatment, which abolishes mROS generation in melanoma cells (27), considerably reduced TRAIL-induced depolarization in a dosedependent manner and this effect was more pronounced for lower concentrations of TRAIL (e.g. $30 \mu \mathrm{M}$ MnTBaP reduced 25 and $100 \mathrm{ng} / \mathrm{ml}$ TRAIL-induced depolarization by $62 \%$ and $48 \%$, respectively). These results show that similar biochemical pathways including upregulation of surface DR5 expression
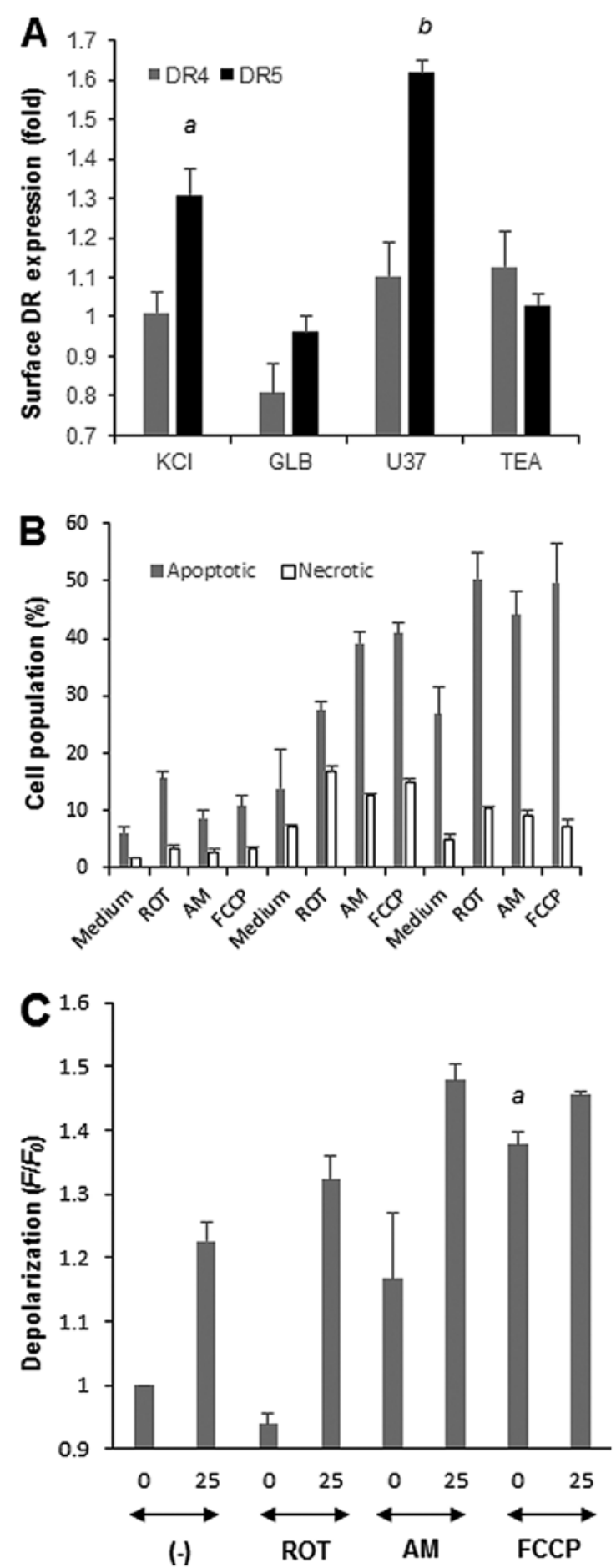

Figure 7. Role of ROS in the depolarization-mediated potentiation of TRAIL-induced apoptosis in human A375 melanoma cells. (A) A375 cells were treated with $\mathrm{KCl}$, U37, GLB or TEA for $20 \mathrm{~h}$, and analyzed for their DR4/DR5 expression levels on the cell surface by indirect immunofluorescence followed by flow cytometry. The fluorescence was measured using the FL-2 channel of the FACSCalibur and analyzed using CellQuest software. The data represent means $\pm \mathrm{SE}(\mathrm{n}=3)$. Letters a and $\mathrm{b}$ indicate statistical significance vs control. (B) Cells were treated with 25 or $100 \mathrm{ng} / \mathrm{ml}$ TRAIL and ROT, AM or FCCP alone or in combination for $20 \mathrm{~h}$, stained with Annexin V-FITC and PI, and analyzed by flow cytometry. Annexin $\mathrm{V}^{+}$cells and Annexin $\mathrm{V}^{-} / \mathrm{PI}^{+}$cells were considered to be apoptotic cells and necrotic cells, respectively. (B) The data represent means $\pm S E(n=3)$. (C) Cells loaded with bis-oxonol were treated with $25 \mathrm{ng} / \mathrm{ml}$ TRAIL and ROT, AM or FCCP alone or in combination for $4 \mathrm{~h}$, and analyzed for their fluorescence by flow cytometry. The data are expressed as $F / F_{0}$, where $F_{0}$ is the fluorescence in unstimulated cells and $\mathrm{F}$ is the fluorescence in stimulated cells, and represent means \pm SE ( $n=3$ or 4$)$. Letter a indicates statistical significance vs control. 


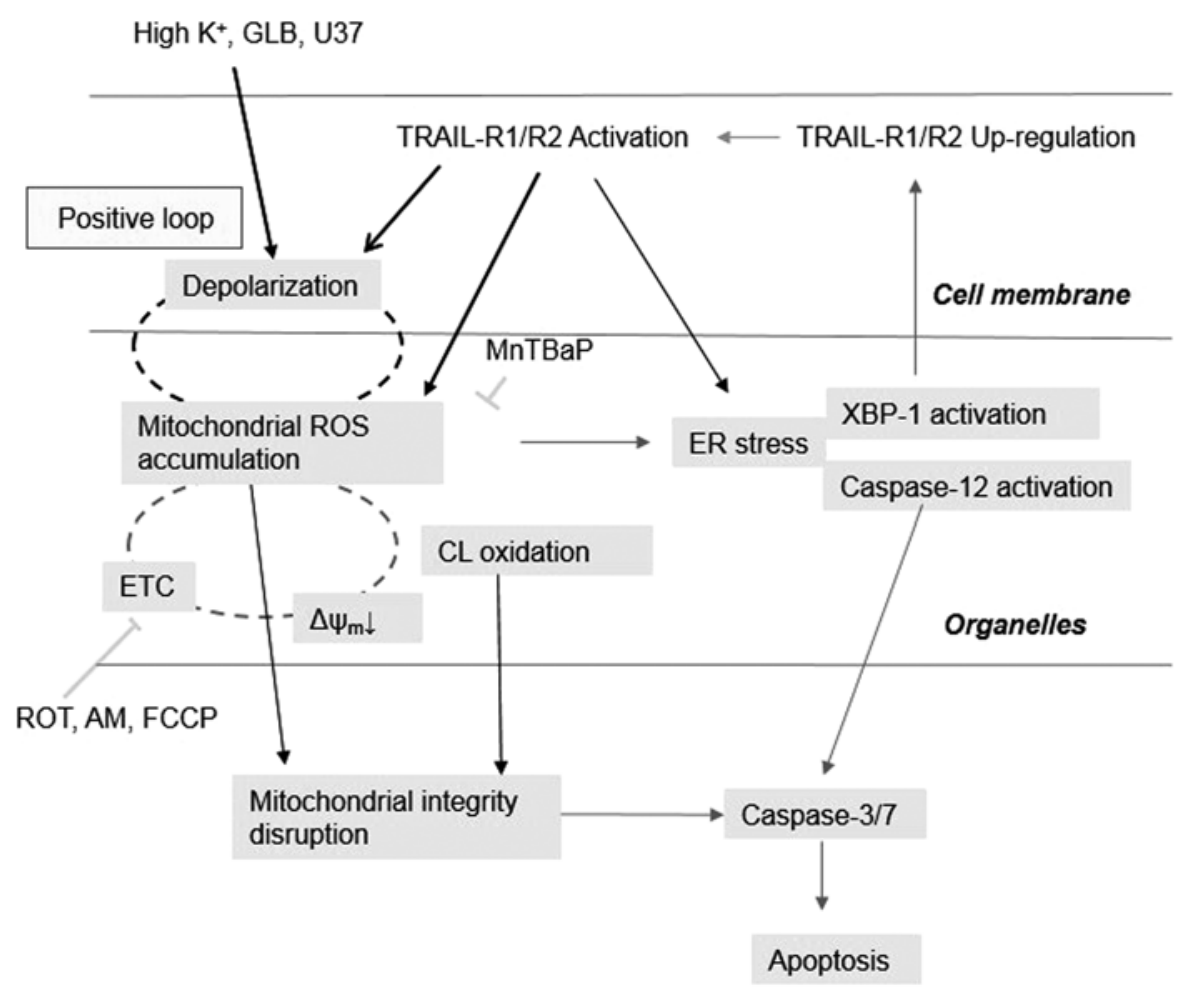

Figure 8. Current model for the positive loop between depolarization and mROS during TRAIL-induced apoptosis in human tumor cells. Triggering TRAIL-R1/R2 induces mROS accumulation, leading to the oxidation of cardiolipin and impairment of electron transport chain (ETC) function. The impairment of complex I/III function decreases $\mathrm{H}^{+}$efflux, thereby causing $\Delta \psi \mathrm{m}$ dissipation. Cardiolipin oxidation and $\Delta \psi \mathrm{m}$ dissipation cooperatively promote mitochondrial integrity disruption and release of apoptogenic proteins such as cytochrome $c$, thereby leading to mitochondrial apoptotic pathway. Accumulated mROS also promote ER stress responses such as the activation of the transcription factor XBP-1 and ER-associated caspase-12 (14). Caspase-12 activation modulates the mitochondrial death pathway, while XBP-1 activation results in upregulation of surface TRAIL-R2 expression. The mROS accumulation and/or $\Delta \psi \mathrm{m}$ dissipation provoke cell membrane depolarization, which upregulates mROS accumulation and surface TRAIL-R2 expression. Consequently, the depolarization-mROS loop contributes to the potentiation of the mitochondrial and ER death pathway, thereby promoting cell death.

and mROS accumulation regulate the depolarization-mediated potentiation of TRAIL-induced apoptosis in the cells.

\section{Discussion}

This study was undertaken to examine whether depolarization plays a general role in TRAIL-induced tumor cell apoptosis, and can therefore serve as a common target for treatment of tumor cells with different origins. The data presented in this paper taken together with our previous data show that membranedepolarizing agents, such as $\mathrm{K}^{+}$and $\mathrm{K}_{\mathrm{ATP}}$ channel inhibitors, potentiate TRAIL-induced apoptosis in human tumor cells with different origins, including Jurkat leukemia cells, and A549 lung cancer cells, but not in non-transformed melanocytes and fibroblsts. Plasma membrane $\mathrm{K}_{\mathrm{ATP}}$ channels appear to be specifically associated with the apoptosis, since inhibitors of other potassium channels, such as $\mathrm{K}_{\mathrm{Ca}}$ and $\mathrm{K}_{\mathrm{v}}$ and mitochondrial $\mathrm{K}_{\text {ATP }}$ channels had no such effect. The findings expand our previous findings for melanoma cells to various types of human malignant cells, and indicate that depolarization may be a tumor-selective target for potentiating apoptosis. This may strengthen the therapeutic potential of membrane-depolarizing agents in cancer treatment. Our previous study showed that membrane-depolarizing agents potentiate TRAIL-induced apoptosis in melanoma cells by upregulating mitochondrial and
ER-associated death pathways (13). The present study indicates that this is a common mechanism at least among certain cell types, including Jurkat cells. In addition, this study provides new insight into the mechanisms by which depolarization potentiates these two death pathways. First, we found that $\mathrm{K}^{+}$ and $\mathrm{K}_{\mathrm{ATP}}$ channel inhibitors commonly upregulated surface DR5 expression in Jurkat cells and A375 melanoma cells, similar to the effects of diverse chemicals such as thapsigargin, tunicamycin and 2-deoxy-D-glucose on melanoma cells (15-17). In contrast, inhibitors of other potassium channels such as TEA had no such effects. Essentially similar results were obtained in A375 melanoma cells. Thus, the upregulation of surface DR5 expression may be relevant to $\mathrm{K}_{\mathrm{ATP}}$ channels function and play a role in the potentiation of apoptosis. Second, we found that the potentiation of death signals is not only caused by quantitative changes but also by qualitative changes. Western blot analyses revealed that depolarization modulated the manner of caspase-3 cleavage, a molecular hallmark of the enzyme activation. TRAIL alone induced cleavage of caspase-3 (35 kDa) to caspase-3 (19 kDa), while under depolarization conditions, TRAIL caused a higher degree of caspase- 3 cleavage, resulting in new appearance of an even smaller form, caspase-3 (17 kDa). The appearance of caspase-3 (19/17 kDa) was completely blocked by specific inhibitors of caspase- 8 and caspase- 9 , as well as caspase-3, consistent with the conventional view that 
caspase-3 activation occurs downstream of extrinsic (caspase-8) and intrinsic (caspase-9) pathways. Caspase-12 is ubiquitously expressed, localized to the ER membrane, and specifically activated by ER stress to play a key role in stress-induced apoptosis (28-30) The caspase-12 inhibitor prevented the cleavage of caspase-3, suggesting that caspase-12 is also involved in the activation of caspase-3. Strikingly, however, the caspase-9 inhibitor prevented the appearance of caspase-3 (17 kDa), but not that of caspase-3 (19 kDa), suggesting that different sets of caspases are involved in the two different manners of caspase-3 cleavage. Thus, depolarization may modulate the caspase cascade pathways involved in caspase- 3 activation. Caspase- 4 , another ER-associated caspase, has also been shown to play a role in ER stress-mediated apoptosis in melanoma cells $(31,32)$. However, the caspase-4-specific inhibitor had minimal effects on the cleavage of caspase-3, suggesting that if caspase- 4 does play a role in the potentiation, it may have another target. Further studies investigating the roles of these two ER-associated caspases in the potentiation are under way.

Our previous findings that mROS mediate mitochondrial and ER dysfunctions in Jurkat cells (14) led us to investigate the possible role of mROS in the potentiation of apoptosis. The membrane-depolarizing agents by themselves increased mROS and potentiated TRAIL-induced mROS generation, indicating that depolarization controls mROS. It is notable that depolarization increased the surface expression of DR5, the triggering of which increases mROS. Since depolarization potentiated the TRAIL-induced activation of the transcription factor XBP-1, which is engaged in the regulation of surface DR5 expression (17), it is possible to speculate that the upregulation of surface DR5 expression results in increased mROS accumulation, thereby causing mitochondrial and ER dysfunctions. On the other hand, our data showed that scavenging of mROS by the antioxidant MnTBaP reduced depolarization, while mROS accumulation caused by metabolic dysfunction potentiated the depolarization. These data indicate that mROS control the depolarization. However, several lines of evidence suggest that this role is limited for weak depolarization. First, depolarization became more resistant to MnTBaP treatment as the concentration of TRAIL (magnitude of depolarization) increased. Second, FCCP-induced depolarization was quite resistant to MnTBaP. It is noteworthy that $5 \mu \mathrm{M}$ FCCP and $100 \mathrm{ng} / \mathrm{ml}$ TRAIL caused comparable levels of mROS accumulation (14) and depolarization (this study), although the time courses of these events were quite different. TRAIL provoked depolarization and mROS accumulation after a considerable time lag, while FCCP caused both responses rapidly. It is noted that FCCP was much more powerful than TRAIL for inducing MMP depolarization. TRAIL induced a moderate MMP depolarization (28\%) with a lag of $2 \mathrm{~h}$, while FCCP caused strong MMP depolarization (92\%) immediately. Taken together with the dose-dependent induction of MMP depolarization by TRAIL, these observations suggest that mROS are responsible for weak depolarization, while another event, probably MMP depolarization is required for strong depolarization. Further studies are necessary to prove this hypothesis. Collectively, our data suggest that depolarization and mROS accumulation mutually regulated one another and that a positive loop exists between the two events (Fig. 8). Although the precise mechanisms underlying the mutual regulation remain to be elucidated, this finding may provide a rationale for the tumor-selective cytotoxicity and/or potentiation of TRAIL cytotoxicity of a wide variety of ROS-producing substances such as wogonin $(33,34)$ and diallyl trisulfide $(35,36)$ in different types of cancer cells including leukemia and melanoma cells.

\section{Acknowledgements}

The authors thank Dr M. Murai and Dr T. Inoue for technical assistance. This study was supported in part by a Grant-in-Aid from the Ministry of Education, Culture, Sports, Science and Technology (KAKENHI 23591631; to Y.S-K.) and Grant-in-Aid from Nihon University (to Y.S-K.).

\section{References}

1. LeBlanc HN and Ashkenazi A: Apo2L/TRAIL and its death and decoy. Cell Death Differ 10: 66-75, 2003.

2. Kischkel FC, Lawrence DA, Chuntharapai A, Schow P, Kim KJ and Ashkenazi A: Apo2L/TRAIL-dependent recruitment of endogenous FADD and caspase- 8 to death receptors 4 and 5 . Immunity 12: 612-620, 2000 .

3. Lavrik IN, Golks A and Krammer PH: Caspases: pharmacological manipulation of cell death. J Clin Invest 15: 2665-2662, 2005.

4. Danial NN and Korsmeyer SJ: Cell death: critical control points. Cell 116: 205-219, 2014.

5. Green DR: Apoptotic pathways: paper wraps stone blunts scissors. Cell 102: 1-4, 2000.

6. Korsmeyer SJ, Wei MC, Saito, M, Weiler S, Oh KJ and Schlesinger PH: Pro-apoptotic cascade activates BID, which oligomerizes BAK or BAX into pores that result in the release of cytochrome $c$. Cell Death Differ 7: 1166-1173, 2000.

7. Yan N and Shi Y: Mechanisms of apoptosis through structural biology. Annu Rev Cell Dev Biol 21: 35-56, 2005.

8. Dyer MJ, MacFarlane M and Cohen GM: Barriers to effective TRAIL-targeted therapy of malignancy. J Clin Oncol 25: 4506-4507, 2007.

9. Bortner CD, Gomez-Angelats M and Cidlowski JA: Plasma membrane depolarization without repolarization is an early molecular event in anti-Fas-induced apoptosis. J Biol Chem 276: 4304-4314, 2001

10. Yin W, Li X, Feng S, et al: Plasma membrane depolarization and $\mathrm{Na}, \mathrm{K}$-ATPase impairment induced by mitochondrial toxins augment leukemia cell apoptosis via a novel mitochondrial amplification mechanism. Biochem Pharmacol 78: 191-202, 2009.

11. Nolte F, Friedrich O, Rojewski M, Fink RH, Schrezenmeier H and Körper S: Depolarisation of the plasma membrane in the arsenic trioxide $\left(\mathrm{As}_{2} \mathrm{O}_{3}\right)$-and anti-CD95-induced apoptosis in myeloid cells. FEBS Lett 578: 85-89, 2004.

12. Ghoumari AM, Piochon C, Tomkiewicz C, et al: Neuroprotective effect of mifepristone involves neuron depolarization. FASEB J 20: 1377-1386, 2006.

13. Suzuki Y, Inoue T, Murai M, Suzuki-Karasaki M, Ochiai T and Ra C: Depolarization potentiates TRAIL-induced apoptosis in human melanoma cells: role for ATP-sensitive $\mathrm{K}^{+}$channels and endoplasmic reticulum stress. Int J Oncol 41: 465-475, 2012.

14. Inoue, $\mathrm{T}$ and Suzuki-Karasaki Y: Mitochondrial superoxide mediates mitochondrial and endoplasmic reticulum dysfunctions in TRAIL-induced apoptosis in Jurkat cells. Free Radic Biol Med 61: 273-284, 2013.

15. Chen LH, Jiang CC, Kiejda KA, et al: Thapsigargin sensitizes human melanoma cells to TRAIL-induced apoptosis by up-regulation of TRAIL-R2 through the unfolded protein response. Carcinogenesis 28: 2328-2336, 2007.

16. Jiang CC, Chen LH, Gillespie S, et al: Tunicamycin sensitizes human melanoma cells to tumor necrosis factor-related apoptosis-inducing ligand-induced apoptosis by up-regulation of TRAIL-R2 via the unfolded protein response. Cancer Res 67: 5880-5888, 2007.

17. Liu H, Jiang CC, Lavis CJ, et al: 2-Deoxy-D-glucose enhances TRAIL-induced apoptosis in human melanoma cells through XBP-1-mediated up-regulation of TRAIL-R2. Mol Cancer 8: 122, 2009. 
18. Boyce $\mathrm{M}$ and Yuan J: Cellular response to endoplasmic reticulum stress: a matter of life or death. Cell Death Differ 13: 363-373, 2006.

19. Breckenridge DG, Germain M, Mathai JP, Nguyen M and Shore GC: Regulation of apoptosis by endoplasmic reticulum pathways. Oncogene 22: 8608-8618, 2003.

20. Groenendyk J and Michalak M: Endoplasmic reticulum quality control and apoptosis. Acta Biochim Pol 52: 381-395, 2005.

21. Robinson KM, Janes MS, Pehar M, et al: Selective fluorescencet imaging of superoxide in vivo using ethidium-based probes. Proc Natl Acad Sci USA 103: 15038-15043, 2006.

22. Mukhopadhyay P, Rajesh M, Kashiwaya Y, Haskó G and Pacher P: Simple quantitative detection of mitochondrial superoxide production in live cells. Biochem Biophys Res Commun 358: 203-208, 2007.

23. Petit JM, Maftah A, Ratinaud MH and Julien R: 10N-nonyl acridine orange interacts with cardiolipin and allows the quantification of this phospholipid in isolated mitochondria. Eur J Biochem 209: 267-273, 1992.

24. Griffith TS, Rauch CT, Smolak PJ, et al: Functional analysis of TRAIL receptors using monoclonal antibodies. J Immunol 162 2597-2605, 1999.

25. Pukac L, Kanakaraj P, Humphreys R, et al: HGS-ETR1, a fully human TRAIL-receptor 1 monoclonal antibody, induces cell death in multiple tumour types in vitro and in vivo. Br J Cancer 92: 1430-1441, 2005.

26. Georgakis GV, Li Y, Humphreys R, et al: Activity of selective fully human agonistic antibodies to the TRAIL death receptors TRAIL-R1 and TRAIL-R2 in primary and cultured lymphoma cells: induction of apoptosis and enhancement of doxorubicin- and bortezomib-induced cell death. Br J Haematol 130: 501-510, 2005.

27. Tochigi M, Inoue T, Suzuki-Karasaki M, Ochiai T, Ra C and Suzuki-Karasaki Y: Hydrogen peroxide induces cell death in human TRAIL-resistant melanoma through intracellular superoxide generation. Int J Oncol 42: 863-872, 2013.
28. Nakagawa T, Zhu H, Morishima N, Li E, Xu J, Yankner BA and Yuan J: Caspase-12 mediates endoplasmic-reticulum-specific apoptosis and cytotoxicity by amyloid beta. Nature 403: 98-103, 2000.

29. Szegezdi E, Fitzgerald U and Samali A: Caspase-12 and ER-stress-mediated apoptosis: the story so far. Ann NY Acad Sci 1010: 186-194, 2003.

30. Rutkowski DT and Kaufman RJ: A trip to the ER: coping with stress. Trends Cell Biol 14: 20-28, 2004.

31. Jiang CC, Mao ZG, Avery-Kiejda KA, Wade M, Hersey P and Zhang XD: Glucose-regulated protein 78 antagonizes cisplatin and adriamycin in human melanoma cells. Carcinogenesis 30 : 197-204, 2009.

32. Mao ZG, Jiang CC, Yang F, Thorne RF, Hersey P and Zhang XD: TRAIL-induced apoptosis of human melanoma cells involves activation of caspase-4. Apoptosis 15: 1211-1222, 2010.

33. Fas SC, Baumann S, Zhu JY, et al: Wogonin sensitizes resistant malignant cells to TNFalpha- and TRAIL-induced apoptosis. Blood 108: 3700-3706, 2006.

34. Baumann S, Fas SC, Giaisi M, et al: Wogonin preferentially kills malignant lymphocytes and suppresses T-cell tumor growth by inducing PLCgamma1- and $\mathrm{Ca}^{2+}$-dependent apoptosis. Blood 111: 2354-2363, 2008.

35. Powlny AA and Singh SV: Multitargeted prevention and therapy of cancer by diallyl trisulfide and related Allium vegetable-derived organosulfur compounds. Cancer Lett 269: 305-314, 2008.

36. Murai M, Inoue T, Suzuki-Karasaki M, Ochiai T, Ra C, Nishida S, et al: Diallyl trisulfide sensitizes human melanoma cells to TRAIL-induced cell death by promoting endoplasmic reticulum-mediated apoptosis. Int J Oncol 41: 2029-2037, 2012. 